\author{
Jian Wen, Ill Yong Kim, Koichi Kikuta \\ and Chikara Ohtsuki \\ Graduate School of Engineering, Nagoya University, B2- \\ 3(611) Furo-cho, Chikusa-ku, Nagoya, 464-8603 Japan \\ Dates: Received: 25 December, 2015; Accepted: \\ 25 January, 2016; Published: 27 January, 2016 \\ *Corresponding author: III Yong Kim, Assistant \\ Professor, Graduate School of Engineering, Nagoya \\ University, B2-3(611) Furo-cho, Chikusa-ku, Nagoya, \\ 464-8603 Japan, Tel: +81-52-789-3183; Fax: +81-52- \\ 789-3182; E-mail: kim.ill-yong@apchem.nagoya-u. \\ ac.jp \\ www.peertechz.com
}

Research Article

\section{Optimization of Sintering Conditions for Improvement of Mechanical Property of $\alpha$-Tricalcium Phosphate Blocks}

\section{Introduction}

Calcium orthophosphates materials have been under research and applied to clinical therapy for several decades. In terms of different types of human bones, various bone substitutes have been developed for the corresponding bones [1-3]. As is well known, human bones consist of two different types of bones, cortical bone and trabecular bone. The hard outer layer of bone is cortical bone (also referred as compact bone), which mainly exists in the shafts of long bones and as a shell around trabecular bone, containing around $80 \%$ of bone mass and facilitating bone's main functions. Trabecular bone (also referred as cancellous or spongy bone) can be found in the ends of long bones, in vertebrae and in flat bones like the pelvis. These two types of bones are classified on the basis of porosity and the unit microstructure. According to a variety of research results, cortical bone has a porosity ranging between $2 \%$ and $27 \%[4,5]$, while trabecular bone is much more porous and the porosity can be as large as $95 \%$ [6]. As for the mechanical properties of the bones, trabecular bone has been reported to exhibit a compressive strength of 2-10 MPa [7], and cortical bone possesses much higher compressive strength, ranging from 100-230 $\mathrm{MPa}$ [8].

Among a variety of calcium phosphates, there are three materials attracting great attention as bone repairing materials, referred as $\alpha$-tricalcium phosphate $\left(\alpha\right.$-TCP, $\left.\alpha-\mathrm{Ca}_{3}\left(\mathrm{PO}_{4}\right)_{2}\right), \quad \beta$-tricalcium phosphate $\left(\beta\right.$-TCP, $\left.\beta-\mathrm{Ca}_{3}\left(\mathrm{PO}_{4}\right)_{2}\right)$ and hydroxyapatite (HAp: $\left.\mathrm{Ca}_{10}\left(\mathrm{PO}_{4}\right)_{6}(\mathrm{OH})_{2}\right)$. Macroporous scaffolds that separately consist of these three types of materials attempting to repair porous bone have been reported in plenty of papers [9-11] and both of porosity and mechanical strength were comparable to those of trabecular bone. However, when it comes to the cortical bone, requirements of repairing material become more complicate. Cortical bone mainly exists in the high load-bearing bones, like tibia and fibula. To repair the damaged sites in these bones, a compressive strength above 150 $\mathrm{MPa}$ of the repairing scaffold is generally demanded [12]. Meanwhile, as a candidate to repair bone, the substitute should be porous, or able to provide porosity after implantation [13]. Nevertheless, ceramic scaffolds get quite brittle when they become porous, making it difficult to reach a balance between the mechanical property and the porosity. More crucially, rapid return of function (formation of new bones) is also a requisite evaluation criteria for bone substitutes, which could bring the patients back to their normal daily life as quickly as possible, minimizing the negative influence to their quality of life. Based on the above three factors, mechanical strength, moderate porosity, biodegradability and osteoconduction are pivotal properties required for an optimal cortical bone substitute.

Among the three materials, $\beta$-TCP and HAp have already been widely used, both in macroporous and dense forms [14,15]. Some previous research has reported dense sintered blocks separately fabricated from $\beta$-TCP and HAp, of which the porosity was less than $1 \%$ and the compressive strength was far higher than that of human cortical bone [8]. Recently, H.O. Mayr et al. [16], reported an intermediate microporous $\beta$-TCP scaffold, which has less porosity (around $43.5 \%$ ) than the macro porous scaffold and the pore size is merely around $5.40 \mu \mathrm{m}$. After seeded with chondrocytes and implanted into a sheep model for one year, $80 \%$ of the scaffold was replaced by new bone. This research provides us a new possible approach to reach a balance between the mechanical strength and porosity suggesting that it may be feasible to fabricate relatively dense 
scaffolds that match both the mechanical properties and porosity of human cortical bone, and in spite the pores are micro porous, the ability to be resorbed and replaced by human body may not be hindered.

As $\alpha$-TCP is relatively newly discovered, it is receiving growing attention because of $\alpha$-TCP has higher dissolution rate than $\beta$-TCP. Besides $\alpha$-TCP transforms easily into HAp by the reaction with $\mathrm{H}_{2} \mathrm{O}$. So, $\alpha$-TCP can be applied to bone cements or an additive in bone cements, although not investigated and applied as widely as the other two materials. The priority of $\alpha$-TCP to $\beta$-TCP or HAp has been reported by several research groups. In regard to the in vitro properties, at $37^{\circ} \mathrm{C}$ and physical $\mathrm{pH}(7.2 \sim 7.4), \alpha$-TCP releases relatively more $\mathrm{Ca}$ and $\mathrm{P}$ and the concentration ranks in the order of $\alpha$-TCP $>\beta$-TCP $>>$ HAp [10,17], implying better ability of providing requisite resources for bone formation. Hisham Rojbani et al. [18], conducted an in vivo experiment of these three materials and confirmed that although $\alpha$-TCP, $\beta$-TCP and HAp were osteoconductive and successfully acted as space maintainer for bone formation when applied to a bone defect and $\alpha$-TCP showed the advantage of higher rate of degradation and more bone formation was observed. Both in vitro and in vivo tests manifested the better potential of $\alpha$-TCP to be resorbed by human body, whereby the return-of-function process may be promoted, especially when a dense structure retards the dissolving of an implant.

Up to present, $\alpha$-TCP are mainly applied in forms of cements and macroporous scaffolds [19], while $\alpha$-TCP-based sintered dense blocks have rarely been investigated or reported. Additionally, the stable temperature of $\alpha$-TCP $\left(1125-1430{ }^{\circ} \mathrm{C}\right)$ differs from that of $\beta$-TCP $(<$ $\left.1250^{\circ} \mathrm{C}\right)$, and $\mathrm{HAp}$ is stable in a wide range of temperature between $800{ }^{\circ} \mathrm{C}$ and $1400^{\circ} \mathrm{C}[20]$ according to various published literature data. Hence, it can be assumed that after sintered into dense forms, the properties of these three materials would also differ with each other. Therefore, the purpose of this research is to fabricate dense a-TCP sintered blocks and investigate the variation of properties under different sintering temperatures, followed by the fabrication of less denser blocks, which have biggest possible porosity meanwhile match with that of cortical bone. Then the samples with both moderate porosity and high compressive strength $(>100 \mathrm{MPa})$ will be chosen for in vitro test in simulated body fluid (SBF), which has ion concentrations nearly equal to those of human blood plasma and was proposed by Kokubo et al. [21], to predict the osteoconduction of the sintered blocks.

\section{Materials and Methods}

\section{Fabrication of sintered blocks from $\alpha$-TCP powder by cold isostatic pressing (CIP) method}

A cold isostatic pressing (CIP) method [22], was utilized to fabricate the dense sintered blocks. $\alpha$-TCP powder ( $\alpha$-TCP-B, Taihei Chem. Inc., Osaka, Japan) was poured into stainless mold ( $\varnothing=7.00$ $\mathrm{mm}$ ) and hand-pressed for preforming. The preformed green cylinders were subsequently encapsulated into rubber finger-cot, evacuated and sealed. The sealed green cylinders were then pressed under pressure of $20 \mathrm{MPa}$ in a pre-established water condition for about $30 \mathrm{~s}$. Afterwards, both ends of the green $\alpha$-TCP cylinders were rubbed to parallel with the horizontal axis. The received green cylinders $(\varnothing=6.15 \mathrm{~mm}$; length $13.50 \mathrm{~mm})$ were sintered under different conditions and the details are given in Table 1.

\section{Fabrication of sintered blocks from $\alpha-\mathrm{TCP} / \mathrm{starch}$ powder by CIP method}

Mixture powder containing $\alpha$-TCP and potato starch (Potato starch, Nacalai tesque, Inc., Kyoto, Japan) was prepared by milling a-TCP and starch powders for 20 minutes. Then green cylinders were received by the above-mentioned CIP method and sintered at different temperatures. Detailed information of the fabrication process are listed in Table 2.

\section{Porosity and shrinkage of the sintered blocks}

The shrinkage of the dense sintered blocks were calculated as:

Shrinkage (\%): $\left.\mathrm{s}=\left(V_{g}-V_{S}\right) / V_{G}\right) \times 100$,

Where $\mathrm{V}_{\mathrm{g}}$ is the volume of the green cylinder and $\mathrm{V}_{\mathrm{s}}$ refers to that of sintered block. The volumes of samples were calculated from diameter and length after sintering. Shrinkages of samples are averaged from the values of 6 samples.

\begin{tabular}{|c|c|c|}
\hline \multicolumn{3}{|c|}{ Table 1: Ion concentrations of simulated body fluid and human blood plasma. } \\
\hline \multirow{2}{*}{$\mathrm{Na}^{+}$} & \multicolumn{2}{|c|}{ lon concentration (mM) } \\
\hline $\mathrm{K}^{+}$ & 142.0 & Blood plasma \\
\hline $\mathrm{Mg}^{2+}$ & 5.0 & 142.0 \\
\hline $\mathrm{Ca}^{2+}$ & 1.5 & 5.0 \\
\hline $\mathrm{Cl}^{-}$ & 2.5 & 1.5 \\
\hline $\mathrm{HCO}_{3}^{-}$ & 147.8 & 2.5 \\
\hline $\mathrm{HPO}_{4}{ }^{2-}$ & 4.2 & 103.0 \\
\hline $\mathrm{SO}_{4}{ }^{2-}$ & 1.0 & 27.0 \\
\hline & 0.5 & 1.0 \\
\hline
\end{tabular}

Table 2: Details of the sintered dense blocks.

\begin{tabular}{|c|c|c|c|c|}
\hline $\begin{array}{c}\text { Temperature } \\
\mathbf{I}^{\circ} \mathbf{C}\end{array}$ & $\begin{array}{c}\text { Heating rate } \mathbf{I} \\
{ }^{\mathbf{}} \mathbf{C} \cdot \mathbf{m i n}^{-1}\end{array}$ & Time $/ \mathbf{h}$ & Porosity / \% & Shrinkage $/ \%$ \\
\hline 1150 & 5 & 12 & $19.20 \pm 2.3$ & $17.55 \pm 1.9$ \\
\hline 1200 & 5 & 12 & $17.66 \pm 1.4$ & $19.90 \pm 1.7$ \\
\hline 1250 & 5 & 12 & $10.85 \pm 0.9$ & $24.00 \pm 1.6$ \\
\hline 1300 & 5 & 12 & $9.75 \pm 1.1$ & $26.38 \pm 1.4$ \\
\hline 1350 & 5 & 12 & $7.68 \pm 0.9$ & $26.28 \pm 1.4$ \\
\hline 1400 & 5 & 12 & $8.30 \pm 0.7$ & $28.45 \pm 1.5$ \\
\hline
\end{tabular}

Table 3: Details of the intermediate porous blocks.

\begin{tabular}{|c|c|c|c|c|c|}
\hline \multirow{2}{*}{$\begin{array}{c}\text { Sample } \\
\text { No. }\end{array}$} & \multicolumn{2}{|c|}{$\begin{array}{c}\text { Composition of } \\
\text { powder / mass } \%\end{array}$} & \multirow{2}{*}{$\begin{array}{l}\text { Heating rate / } \\
{ }^{\circ} \mathrm{C} \cdot \mathrm{min}^{-1}\end{array}$} & \multirow{2}{*}{$\begin{array}{c}\text { Keeping } \\
\text { time / h }\end{array}$} & \multirow{2}{*}{$\begin{array}{c}\text { Tempera- } \\
\text { ture } \\
I^{\circ} \mathrm{C}\end{array}$} \\
\hline & $\alpha-\mathrm{TCP}$ & Starch & & & \\
\hline $91 / 1300$ & 90 & 10 & 5 & 12 & 1300 \\
\hline $91 / 1250$ & 90 & 10 & 5 & 12 & 1250 \\
\hline $91 / 1200$ & 90 & 10 & 5 & 12 & 1200 \\
\hline $91 / 1150$ & 90 & 10 & 5 & 12 & 1150 \\
\hline $82 / 1150$ & 80 & 20 & 5 & 12 & 1150 \\
\hline $73 / 1150$ & 70 & 30 & 5 & 12 & 1150 \\
\hline
\end{tabular}


The total porosity of all sintered blocks were calculated by Equation:

Total porosity $(\%): \varepsilon=\left(1-\rho_{b} / \rho_{s}\right) \times 100$,

Where $\rho_{\mathrm{b}}$ is the density of the porous scaffold calculated by weight and volume, $\rho_{\mathrm{s}}$ is the theoretical density of $\alpha-\mathrm{TCP}\left(2.83 \mathrm{~g} / \mathrm{cm}^{3}\right)$. While apparent porosity of some samples $(n=6)$ were measured through an Archimedes method (according to ASTM C373-88) with kerosene used as a liquid medium and the porosity was expressed as:

Apparent porosity (\%): $\varepsilon=\left(W_{3}-W_{1}\right) /\left(W_{3}-W_{2}\right) \times 100$,

Where $W_{1}$ is the weight of sample in air, $W_{2}$ is the weight of sample suspended in kerosene and $\mathrm{W}_{3}$ is the saturated weight, and calculated from the density and sample size.

\section{Immersion test}

The 91/1150 samples were soaked in $40 \mathrm{~cm}^{3} \mathrm{SBF}$ solutions for $0,1,3,7$ and $14 \mathrm{~d}$, respectively. Composition of SBF with ion concentrations nearly equal to those of human blood plasma as shown in Table 1 [21]. The SBF was prepared by dissolving reagent grade chemicals of $\mathrm{NaCl}, \mathrm{NaHCO}_{3}, \mathrm{KCl}, \mathrm{K}_{2} \mathrm{HPO}_{4} \cdot 3 \mathrm{H}_{2} \mathrm{O}, \mathrm{MgCl}_{2} \cdot 6 \mathrm{H}_{2} \mathrm{O}$, $\mathrm{CaCl}_{2}$ and $\mathrm{Na}_{2} \mathrm{SO}_{4}$ into distilled water. It was buffered at $\mathrm{pH} 7.4$ with $50 \mathrm{mmol}$ tris(hydroxymethyl)aminomethane $\left(\left(\mathrm{CH}_{2} \mathrm{OH}\right)_{3} \mathrm{CNH}_{2}\right)$ and $45 \mathrm{mM}$ hydrochloric acid $(\mathrm{HCl})$ and was kept at $36.5^{\circ} \mathrm{C}$. After removal of samples from SBF, the variation of $\mathrm{Ca}, \mathrm{P}$ and $\mathrm{Mg}$ concentrations in the solutions $(n=5)$ were measured by induced coupled plasma atomic emission spectroscopy (ICP-AES; Optima 2000DV, PerkinElmer Japan Co. Ltd., Japan). After soaking, the blocks were dried at $100{ }^{\circ} \mathrm{C}$ for $12 \mathrm{~h}$, followed by a vacuum-drying process at $100 \mathrm{C}$ for $24 \mathrm{~h}$ to calculate the weight changes before and after soaking.

\section{Mechanical strength measurement}

Compressive strength and Young's modulus of all samples were measured by an Instron Model 5566 system with a crosshead speed of $1 \mathrm{~mm} / \mathrm{min}$ and the load cell was $10 \mathrm{kN}$. Each value used in this study was the average data of 6 specimens.

\section{Crystal phases and morphologies}

After sintering process and immersing process, crystal phases of the sintered blocks were tested by powder X-ray diffraction (XRD; RINT2100,Rigaku Co., Japan) using CuKa radiation with a scanning speed of $2 \% \mathrm{~min}$ at $40 \mathrm{kV}$ and $20 \mathrm{~mA}$ after ground into fine powder using a mortar. Morphologies of all the specimens were observed by scanning electron microscopy (SEM; JSM-5600, JEOL Ltd, Tokyo, Japan) at a $15 \mathrm{kV}$ operating voltage after gold sputter-coating.

\section{Results}

\section{Dense sintered blocks prepared from $\alpha$-TCP}

The images of the green cylindrical bodies and sintered blocks are shown in Figure 1. The porosity and shrinkage of the dense sintered blocks are shown in Table 1. It is plain to see that as the sintering temperature increased, the blocks shrank and the porosity dropped from $19.2 \%$ to $8.3 \%$, implying that sintered blocks became denser. The compressive strength are given in Figure 2. A turning point of the compressive strength can be found around $1300{ }^{\circ} \mathrm{C}$. The average compressive strength of the blocks sintered between 1150 and 1300

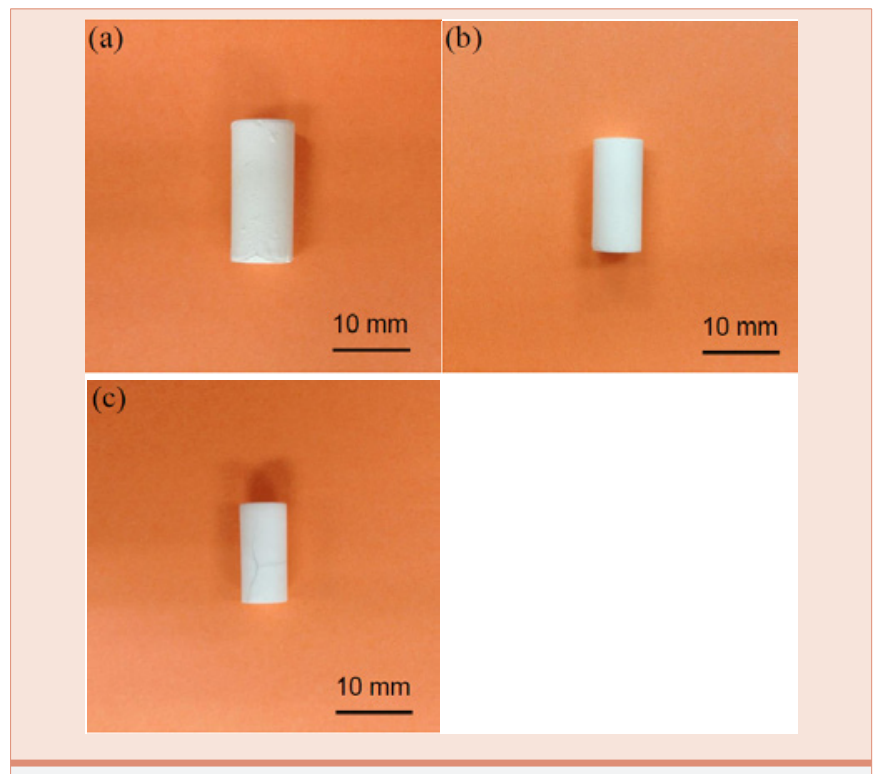

Figure 1: Images of green blocks (a) and sintered dense blocks. (b) $1150{ }^{\circ} \mathrm{C}$, (c) $1400^{\circ} \mathrm{C}$.

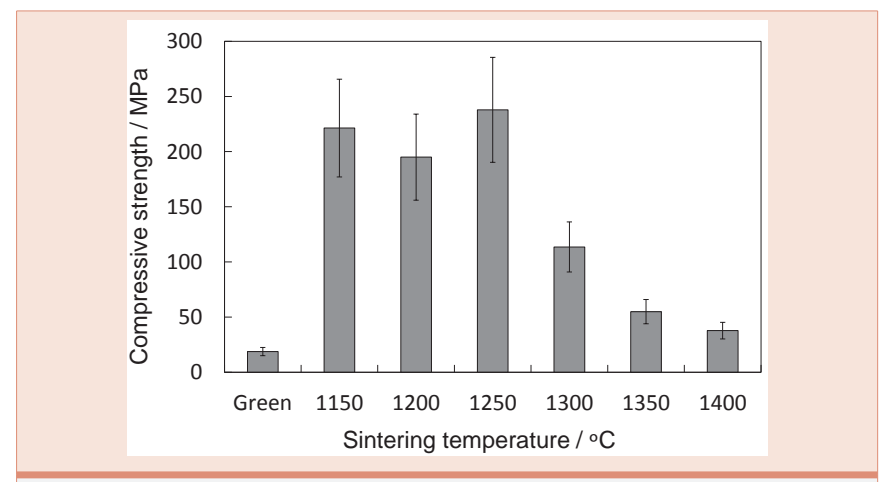

Figure 2: Compressive strength of dense blocks sintered between 1150 and $1400^{\circ} \mathrm{C}$.

${ }^{\circ} \mathrm{C}$ exceeded $100 \mathrm{MPa}$, however, decreased precipitously at 1300 ${ }^{\circ} \mathrm{C}$-from about $230 \mathrm{MPa}$ to $110 \mathrm{MPa}$, and fell further down below 100 $\mathrm{MPa}$ when the temperature came to $1350^{\circ} \mathrm{C}$.

After sintered at different temperature varying from $1150{ }^{\circ} \mathrm{C}$ to $1400{ }^{\circ} \mathrm{C}$, the crystal phase of the samples were analyzed by XRD (Figure 3). In samples sintered between $1250{ }^{\circ} \mathrm{C}$ and $1400{ }^{\circ} \mathrm{C}$, no other than peaks corresponding to $\alpha$-TCP were detected. Although $\alpha$-TCP phase was the main phase, there were still small amount of peaks corresponding to $\beta$-TCP presented in the samples sintered at $1150{ }^{\circ} \mathrm{C}$ and $1200{ }^{\circ} \mathrm{C}$. Through the surface SEM images (Figure 4 $\mathrm{b}, \mathrm{c}, \mathrm{d})$ of the sintered blocks, it can be observed that the grains grew as the temperature went higher, from about $3 \mu \mathrm{m}$ up to around $15 \mu \mathrm{m}$. The cross-section SEM images (Figure 4e,f,g) showed a proceeding densification in the sintering process. With the sintering temperature increasing, the quantity of the pores declined and the interconnected pores gradually became isolated, which matched the tendency of the porosity. 


\section{Dense sintered blocks prepared from $\alpha-$ TCP and starch}

Green cylinders containing 90 mass $\%$ a-TCP and 10 mass $\%$ were sintered between $1150{ }^{\circ} \mathrm{C}$ and $1300^{\circ} \mathrm{C}$. The total porosity and apparent porosity were measured and shown in Figure 5. The porosity ranges between $22 \%$ and $35 \%$, in which apparent porosity was slightly, about $3 \%$ lower than total porosity, indicating that most pores are interconnected. The highest compressive strength was obtained in the $91 / 1300$ samples yet those of other samples were also successfully maintained above $100 \mathrm{MPa}$. As the content of starch rose up to 20 mass\%, the compressive strength dropped quickly below $100 \mathrm{MPa}$. In the cross-section SEM images of the sintered blocks (Figure $6 \mathrm{a}, \mathrm{b}, \mathrm{c}$ )), pores $(20 \mu \mathrm{m} \sim 80 \mu \mathrm{m})$ caused by starch could be observed and were interconnected through the naturally generated pores (around $5 \mu \mathrm{m}$ ).

The 91/1150 group samples were soaked in SBF solutions for $1,3,7$ and $14 \mathrm{~d}$ for in vitro evaluation. After immersing and drying process, each sample gained weight, as shown in Figure 7, and the extra weight increased along with immersion period. As for the compressive strength, it continued dropping downward in the initial 7 days and did not recover until $14 \mathrm{~d}$, yet still lower than the initial strength. The changes in crystalline phases after immersion are

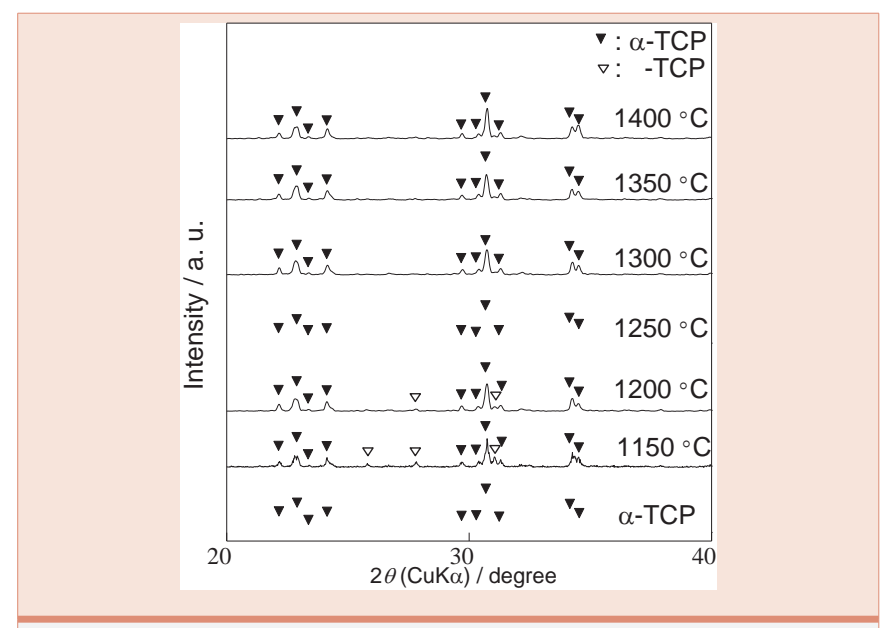

Figure 3: XRD patterns of starting powder $\alpha-T C P$ and samples after sintering between 1150 and $1400{ }^{\circ} \mathrm{C}$.

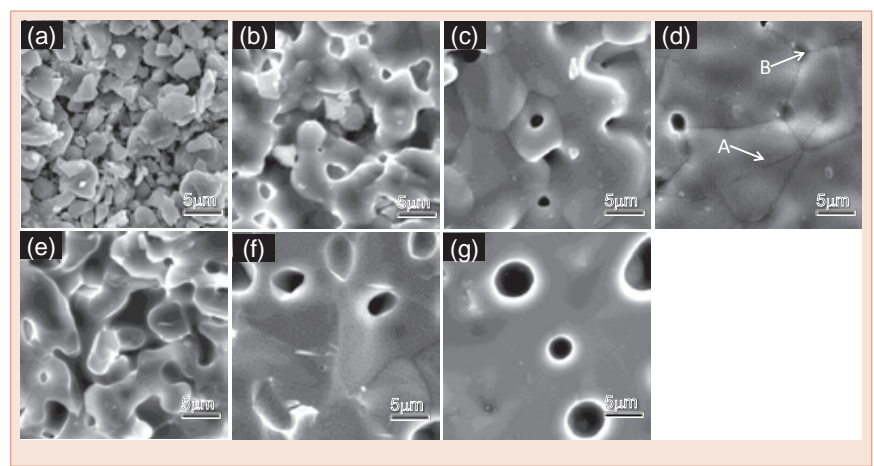

Figure 4: SEM images of green blocks (a) and dense sintered blocks. Surface: (b) $1150{ }^{\circ} \mathrm{C}$, (c) $1300 \mathrm{C}$, (d) $1400{ }^{\circ} \mathrm{C}$. Cross-section: (e) $1150{ }^{\circ} \mathrm{C}$, (f) $1300{ }^{\circ} \mathrm{C}$, (g) $1400 \mathrm{C}$.

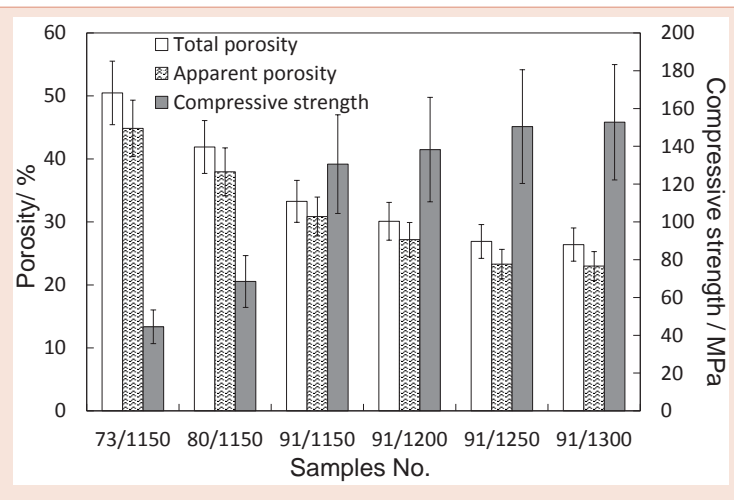

Figure 5: Total porosity, apparent porosity and compressive strength of the intermediate porous sintered blocks.

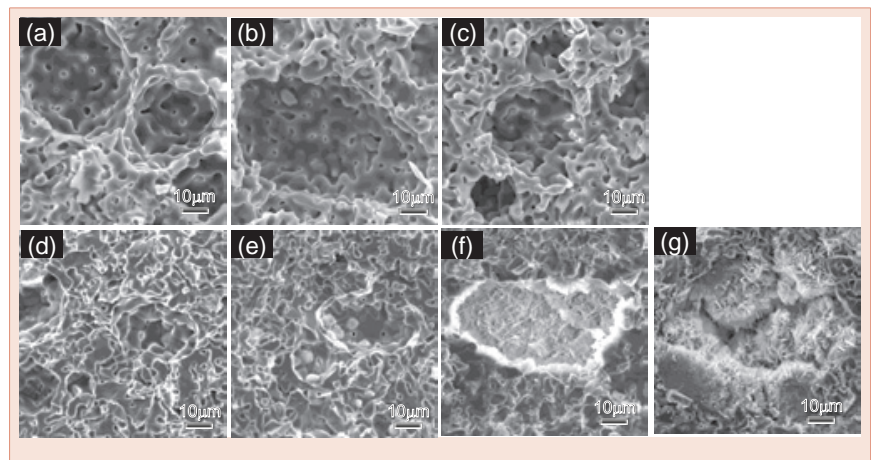

Figure 6: Cross-section SEM images of the sintered intermediate porous blocks. (a) 73/1150, (b) 82/1150, (c) 91/1150. (d), (e), (f) and (g) are crosssection SEM images of $91 / 1150$ samples after soaking for $1,3,7$ and $14 \mathrm{~d}$, respectively.

given in Figure 9. With soaking periods extending, the pre-existing peaks corresponding to $\beta$-TCP gradually strengthened. Conversely, those of $\alpha$-TCP weakened and some of the peaks even disappeared. In the $14 \mathrm{~d}$ samples, peaks corresponding to HAp were detected. The morphology of the in vitro tested samples are shown in Figure 8. Except for the $1 \mathrm{~d}$ soaked samples, newly formed crystalline were observed in all samples, mainly in and around the pores. Relatively more new crystalline were observed in $7 \mathrm{~d}$ and $14 \mathrm{~d}$ samples.

$\mathrm{Ca}, \mathrm{P}$ and $\mathrm{Mg}$ concentrations in SBF solutions before and after the immersion test were measured by ICP-AES and shown in Figure 10. Ca concentration in SBF slightly and gradually increased up to 14 d. On the contrary, the P and $\mathrm{Mg}$ concentrations showed analogous downward tendency but the declining rates were faster than the increase rate of Ca concentration.

\section{Discussion}

\section{Dense sintered blocks prepared from $\alpha$-TCP}

The porosity of the dense sintered blocks falls as the sintering temperature increases, implying a proceeded sintering process. From the surface SEM images (Figure 4b,c,d) it can be seen that the isolated grains in the green cylinders gradually merge with adjacent grains and grain sizes also grow from about $3.00 \mathrm{~m}$ to around $15.00 \mu \mathrm{m}$. 


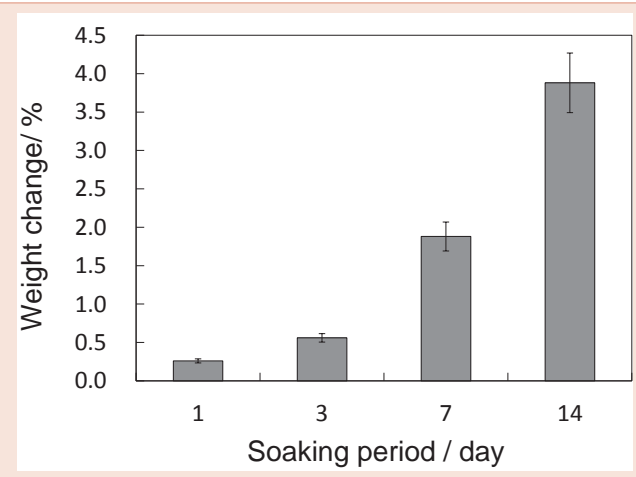

Figure 7: Weight changes of 91/1150 samples after soaking for $1,3,7$ and 14 d, respectively.

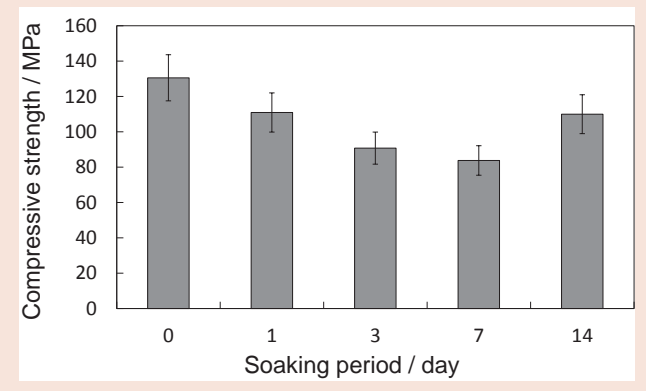

Figure 8: Compressive strength variation of 91/1150 samples before and after soaking for $1,3,7$ and $14 \mathrm{~d}$, respectively.

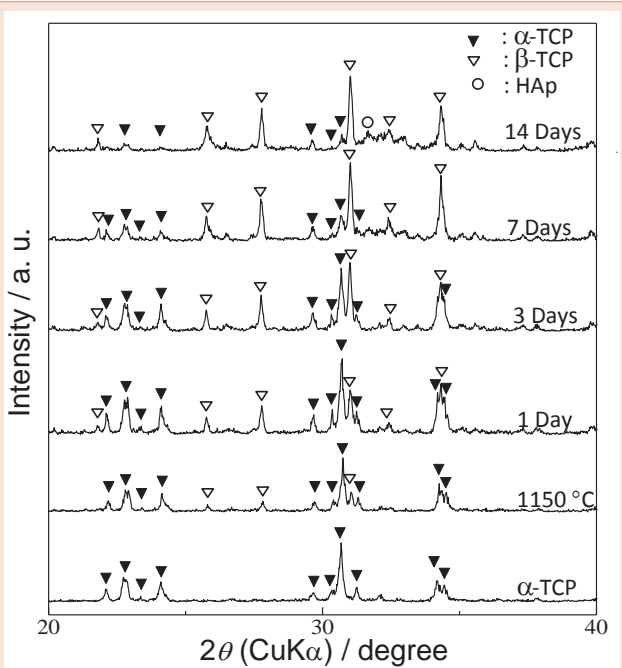

Figure 9: Crystalline phases changes of 91/1150 samples before and after soaking for $1,3,7$ and $14 \mathrm{~d}$, respectively.

Together with the cross-section SEM images (Figure 4b,c,d)) ,it can be observed that sintering process is accompanied by densification of the blocks, during which the amount of pores goes down and the channels of the interconnected pores slowly collapsed to become isolated. However, the compressive strength, as shown in Figure 2, does not increase with the proceeding sintering process. Although the compressive strength of four groups $\left(1150,1200,1250\right.$ and $\left.1300^{\circ} \mathrm{C}\right)$ exceeds the minimum value (100 MPa) of human cortical bone, the compressive strength drops dramatically at $1300{ }^{\circ} \mathrm{C}$, from $230 \mathrm{MPa}$ to $110 \mathrm{MPa}$, and further decrease below $100 \mathrm{MPa}$ when temperature become higher than $1350{ }^{\circ} \mathrm{C}$. A. Tricoteaux et al. [23], reported a $\beta$-TCP slip (porosity: $0 \sim 14 \%$ ), and the mechanical strength increased as the porosity decreased. The results of this research, in contrary, show a opposite tendency. This unexpected phenomenon could be attributed to internal stresses. A common source of internal stresses in ceramic materials is the thermal expansion anisotropy. In some cases residual stresses are large enough to produce microcracking along grain boundaries or macrocrack propagation [24].

In this research, macrocracks are frequently observed on the blocks sintered at $1350{ }^{\circ} \mathrm{C}$ and $1400{ }^{\circ} \mathrm{C}$, as shown in Figure 1c). It can be deduced that in the preservation stage of sintering process, the temperature of the cylinder surface is same as that of the center and thermal stress is not generated. During the cooling stage, the surface cools faster and contracts more than the center, bringing about tensile stress on the surface and produce compressive stress in the center. When the tensile stress is large enough and exceeds the tensile strength, macrocracks are usually produced. As can be seen in Figure 4, the sintering process does not proceed optimally, during which the grains grow inhomogeneously and microscopic stress may occur between and in the adjacent grains, leading to the microcracks along the grain boundary (boundary crack, arrow A), and some grains are directly broken by this microscopic stress (cleavage crack, arrow B). In addition, the size of these two types of microcracks is positively correlative with the size of the grain, implying that the cracks propagate with the growth of the grain. The relation between the fracture strength and grain size of a ceramic material is researched by S. Mizuta et al. [25], and expressed as an empirical equation:

$$
\sigma_{f}=\sigma_{0}+k d^{-1 / 2} \text {, }
$$

Where $\sigma_{\mathrm{f}}$ is the fracture strength, $\mathrm{d}$ is the grain size, $\sigma_{0}$ and $\mathrm{k}$ are constants. It can be deduced from this equation that a larger sized grain can engender negative effects on the mechanical strength of a dense sintered cylinder. When the cylinder is compressively pressed, the above-mentioned macro and micro cracks both propagate, thus rendering the entire failure of the blocks. Meanwhile, relatively higher compressive strength exhibited in the cylinders sintered

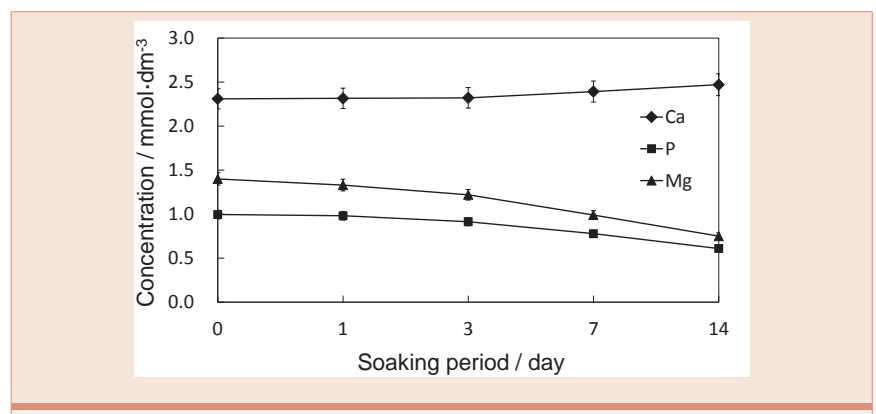

Figure 10: Concentrations of $\mathrm{Ca}, \mathrm{P}$ and $\mathrm{Mg}$ in $\mathrm{SBF}$ solution after soaking $91 / 1150$ samples for $1,3,7$ and $14 \mathrm{~d}$, respectively. 
between $1150{ }^{\circ} \mathrm{C}$ and $1250^{\circ} \mathrm{C}$ may be ascribed to the higher porosity. The interconnected pores provide spaces for the grains to deform and migrate towards pore spaces instead of being enclosed and extruded by adjacent grains, conducing to release the thermal and microscopic residual stresses.

\section{Dense sintered blocks prepared from $\alpha$-TCP and starch}

In order to increase the porosity of the sintered blocks to match with that of human cortical bone, $a$-TCP and starch are mixed for sintering. Sintering temperature are controlled between $1150^{\circ} \mathrm{C}$ and $1300{ }^{\circ} \mathrm{C}$, through which pores are interconnected and compressive strength is above $100 \mathrm{MPa}$. Both total porosity and apparent porosity are measured and shown in Figure 5. The porosity of the 91/1150 samples is exactly a little bit higher than that of human cortical bone. Apparent porosity is slightly lower than total porosity, indicating that most pores are interconnected and may provide spaces for circulation of nutrients and exhaust of metabolic waste. The increase of the porosity is accompanied with different degrees of strength reduction, yet except the $73 / 1150$ and $82 / 1150$ samples, the compressive strength of other samples are maintained above $100 \mathrm{MPa}$. The naturally generated pores $(<5 \mu \mathrm{m})$ in the sintering process are generally deemed to be difficult for cells to attach and migrate, but useful for the protein attachment and cell adhesive [26]. In this research, the starch mixed with $\alpha$-TCP not only increase the porosity, but also produce pores with sizes ranging from 30 to $90 \mu \mathrm{m}$ (Figure $6 \mathrm{a}, \mathrm{b}, \mathrm{c})$ ). The size of these pores are comparable to that of human average cell size (74.66 $\sim 82.45 \mu \mathrm{m})$ [27], especially for that of osteoclast $(20 \sim 150 \mu \mathrm{m})$ [28], which will be suitable for osteoclast to migrate in the pores and resorb the bone-like materials, thus leaving space for osteoblast $(10 \sim 50 \mu \mathrm{m})$ [29], to make new bone tissues.

Taking both compressive strength and porosity into account, the $91 / 1150$ samples, which have the most porous structure in the above-100 MPa samples, are chosen for the in vitro immersion test in SBF solutions up to $14 \mathrm{~d}$. A possible reason that each sample gains weight after soaking is the newly formed crystalline, as shown in (Figure 6d,e,f,g)), and the amount of observed crystalline is proportional to the extra weight. The compressive strength of samples keep declining up to $7 \mathrm{~d}$ and do not rebound above 100 MPa until 14d, yet lower than the initial compressive strength. As immersion proceeds, crystalline phases of the samples change, but not as expected. There are no peaks corresponding to HAp being detected until the $14 \mathrm{~d}$ meanwhile $\alpha$-TCP peaks gradually weaken and by $14 \mathrm{~d}$ the $\beta$-TCP become the main phase. Putting this phase change and the weight change together into consideration it can be presumed that $\alpha$-TCP dissolve in SBF solution and the released $\mathrm{Ca}^{2+}$ and $\mathrm{PO}_{4}^{3-}$ along with the pre-existing $\mathrm{Ca}^{2+}$ and $\mathrm{HPO}_{4}{ }^{2-}\left(\mathrm{HPO}_{4}{ }^{2-}\right.$ $\left.\rightarrow \mathrm{H}^{+}+\mathrm{PO}_{4}^{3-}\right)$ in SBF recrystallize and form $\beta$-TCP. To confirm this assumption, $\mathrm{Ca}$ and $\mathrm{P}$ concentrations in SBF are measured and should simultaneously decline as expected. However, as can be seen in Figure 10 , only concentration of $\mathrm{P}$ decreases and contrarily concentration of $\mathrm{Ca}$ slightly increases. In regard to this phenomenon, we paid attention to a $\beta$-TCP analogue, referred as Mg-whitlockite (Mg$\beta$-TCP, $\left.(\mathrm{Ca}, \mathrm{Mg})_{3}\left(\mathrm{PO}_{4}\right)_{2}\right)$, in which calcium is partly substituted by magnesium. Mg-whitlockite has been commonly found in biological conditions as well as fabricated for research [30,31]. For this reason the concentration of $\mathrm{Mg}$ is subsequently measured and the result shows that concentration of $\mathrm{Mg}$ in SBF presents a similar downward tendency with $\mathrm{P}$, indicating that the substitution of Ca by $\mathrm{Mg}$ actually occurs in the immersion process and contributes to the increase of $\mathrm{Ca}$ concentration.

\section{Conclusion}

Both dense and intermediate porous $\alpha$-TCP blocks were fabricated through cold isostatic pressing followed by a sintering process (1150 $\sim 1400{ }^{\circ} \mathrm{C}$ ). The dense blocks reached a highest compressive strength $(230 \mathrm{MPa})$ after sintering at $1250^{\circ} \mathrm{C}$ and it dropped steeply with higher sintering temperature. The decrease in compressive strength might be attributed to the thermal residual stress, the microscopic residual stress between grains and the growth of the grains. Intermediate porous blocks (compressive strength $135 \mathrm{MPa}$, porosity 33\%) were soaked in simulated body fluid for in vitro test. The compressive strength kept decreasing at first and by $14 \mathrm{~d}$ it rebounded to around $110 \mathrm{MPa}$. $\alpha$-TCP gradually dissolved and transformed into $\beta$-TCP, in which Ca was partially substituted by $\mathrm{Mg}$ in SBF solution. HAp formation was not observed until the soaking process lasted for $14 \mathrm{~d}$.

\section{Acknowledgements}

This work was partially supported by Gran-in-Aid for Scientific Research (No. 22107007) on Innovative Areas of "Fusion Materials (Area No. 2206) from the Ministry of Education, Culture, Sports, Science and Technology, Japan (MEXT) and Hirose International scholarship foundation, Japan.

\section{References}

1. Alberto JA, Leonard M. (2006) Calcium phosphate cement: Review of mechanical and biological properties. J. Prosthod $15: 321-328$

2. Ginebra M-P, Canal C, Espanol M, Pastorino D, Montufar EB. (2012) Calcium phosphate cement as drug delivery materials, Adv Drug Delivery Rev 64 : 1090-1110

3. Barinov SM, Komlev VS. (2011) Calcium phosphate bone cements, Inorg Mater 47 : 1470-1485

4. Wang XD, Ni QW. (2003) Determination of cortical bone porosity and pore size distribution using a low field pulsed NMR approach. J Orthop Res 21: 312-319

5. Cooper DML, Matyas JR, Katzenberg MA, Hallgrimsson B. (2004) Comparison of microcomputed tomographic and microradiographic measurements of cortical bone porosity. Calcified Tissue Int 74: 437-447

6. Snyder BD, Piazza S, Edwards WT, Hayes WC. (1993) Role of trabecular morphology in the etiology of agerelated vertebral fractures. Calcified Tissue Int 53: 14-22.

7. Gibson LJ. (1985) The mechanical behavior of cancellous bone. J Biomech 18: $317-328$

8. Hench LL. (1998) Bioceramics. J Am Ceram Soc 81: 1705-1728

9. Uchino T, Yamaguchi K, Suzuki I, Kamitakahara M, Otsuka M, Ohtsuki C. (2010) Hydroxyapatite formation on porous ceramics of alpha-tricalcium phosphate in a simulated body fluid. J Mater Sci: Mater Med 21: 1921-1926

10. Panzavolta S, Fini M, Nicoletti A, Bracci B, Rubini K, Giardino R, Bigi A. (2009) Porous composite scaffolds based on gelatin and partially hydrolyzed a-tricalcium phosphate. Acta Biomater 5: 636-643

11. Sun FF, Zhou HJ, Lee J. (2011) Various preparation methods of highly porous 
hydroxyapatite/polymer nanoscale biocomposites for bone regeneration Acta Biomater 7: 3813-3828

12. Takeoka Y, Hayashi M, Sugiyama N, Yoshizawa-Fujita M, Aizawa M Rikukawa M. (2015) In situ preparation of poly(I-lactic acid-co-glycolic acid)/ hydroxyapatite composites as artificial bone materials, Polym J 47 : 164-170

13. Saiz E, Zimmermann EA, Lee JS, Wegst UGK, Tomsia AP. (2013) Perspectives on the role of nanotechnology in bone tissue engineering. Dent Mater 29: 103-115

14. Barralet JE, Grover L, Gaunt T, Wright AJ, Gibson IR. (2002) Preparation of macroporous calcium phosphate cement tissue engineering scaffold Biomaterials 23 : 3063-3072

15. Milosevski M, Bossert J, Milosevski D, Gruevska N. (1999) Preparation and properties of dense and porous calcium phosphate. Ceram Inter 25 693-696

16. Mayr HO, Klehm J, Schwan S, Hube R, Südkamp NP, Niemeyer P, Salzmann G, von Eisenhardt-Rothe R, Heilmann A, Bohner M, Bernstein A. (2013) Microporous calcium phosphate ceramics as tissue engineering scaffolds for the repair of osteochondral defects: Biomechanical results. Acta Biomater 9:4845-4855

17. Chow LC. (1991) Development of self-setting calcium phosphate cements. $J$ Ceram Soc Japan 99: 954-64

18. Rojbani H, Nyan M, Ohya K, Kasugai S. (2011) Evaluation of the osteoconductivity of $\alpha$-tricalcium phosphate, $\beta$-tricalcium phosphate and hydroxyapatite combined with or without simvastatin in rat calvarial defect. $J$ Biomed Mater Res A 98A: 488-498

19. Carrodeguas RG, De Aza S. (2011) a-Tricalcium phosphate: Synthesis, properties and biomedical applications. Acta Biomater 7: 3536-3546

20. Suchanek W, Yashima M, Kakihana M, Yoshimura M. (1997) Hydroxyapatite ceramics with selected sintering additives. Biomaterials 18: 923-933
21. Kokubo T, Takadama H. (2006) How useful is SBF in predicting in vivo bone bioactivity. Biomaterials 27: 2907-2915

22. Prokhorov IY, Akimov GY. (1997) Cold isostatic pressing as a method of preforming green ceramic ware. J Eur Ceram Soc 17: 129-131

23. Tricoteaux A, Rguiti E, Chicot D, Boilet L, Descamps M, Leriche A, Lesage J. (2011) Influence of porosity on the mechanical properties of microporous $\beta$-TCP bioceramics by usual and instrumented Vickers microindentation. J Eur Ceram Soc 31: 1361-1369

24. Luo J, Stevens R. (1993) Residual stress and microcracking in SiC-MgO composites. J Eur Ceram Soc 12: 369-375

25. Mizuta S, Koumoto K. (1996) Material Science for Ceramics. 1st edition. University of Tokyo Press.

26. Vitale-Brovarone C, Verne E, Robiglio L, Appendino P, Bassi F, Martinasso G, Muzio G, Canuto R, (2007) Development of glass-ceramic scaffolds for bone tissue engineering: Characterisation, proliferation of human osteoblasts and nodule formation. Acta Biomater 3: 199-208

27. Groessner-Schreiber B, Krukowski M, Lyons C, Osdoby P. (1992) Osteoclast recruitment in response to human bone matrix is age related. Mech Ageing Dev 62: 143-154

28. Jandl JH. (1996) Blood: Textbook of Hematology, 2nd edition. Little Brown and Company, Boston, MA.

29. Cooper LF, Handelman B, McCormack SM, Guckes AD. (1993) Binding of murine osteoblastic cells to titanium disks and collagen I gels: implications for alternative interpretations of osseointegration. Int J Oral Max Impl 8: 264-72

30. Lagier R, Baud CA. (2003) Magnesium whitlockite, a calcium phosphate crystal of special interest in pathology. Pathol Res Pract 199: 329-335

31. Li X, Ito A, Sogo Y, Wang XP, LeGeros RZ. (2009) Solubility of Mg-containing $\beta$-tricalcium phosphate at $25^{\circ} \mathrm{C}$. Acta Biomater 5: 508-517.

Copyright: (c) 2016 Wen J, et al. This is an open-access article distributed under the terms of the Creative Commons Attribution License, which permits unrestricted use, distribution, and reproduction in any medium, provided the original author and source are credited. 